\title{
Pamukkale Üniversitesi Hastanesi Kadın Hastalıkları ve Doğum Polikliniği'ne başvuran hastaların servikal smear sonuçlarının değerlendirilmesi
}

\author{
Evaluation of cervical smear results of patients who were admitted to Pamukkale \\ University hospital obstetrics and gynecology outpatient clinic
}

\author{
Özlem Koşar Can
}

Öz

Amaç: Bu çalışma Pamukkale Üniversitesi Hastanesi Kadın Hastalıkları ve Doğum Polikliniği'ne başvuran hastalardan alınan pap smear sonuçlarını değerlendirmek için planlandı.

Gereç ve yöntem: Pamukkale Üniversitesi Hastanesi Kadın Hastalıkları ve Doğum Polikliniği'ne Haziran 2018 ile Ağustos 2021 tarihleri arasında başvuran kadınların Sure Path yöntemiyle hazırlanan, Bethesda 2014 Sistemi'ne göre raporlandırılmış pap smear sonuçları retrospektif olarak incelendi.

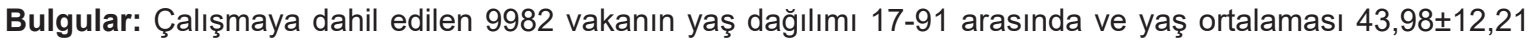
idi. Toplam $9572(\% 95,89)$ kadının sonucu normal olarak saptandı. Bu çalışmada, anormal smear oranı \%1,97; önemi belirsiz atipik skuamoz hücreler, yüksek dereceli lezyonun dışlanamadığı atipik skuamoz lezyon, düşük dereceli skuamöz intraepitelial lezyon, yüksek dereceli skuamöz intraepitelial lezyon ve atipik glandüler hücreler oranı sırasıyla \%0,98, \%0,25, \%0,56, \%0,17 ve \%0,01 idi.

Sonuç: Bu çalışmada anormal smear oranı $(\% 1,97)$ Türk Servikal Kanser ve Servikal Sitoloji Araştırma Grubu'nun 2009 yılında yayınlanan 33 merkezin dahil olduğu çalışmaya göre yüksek bulunmuştur. Bunun nedeni Pamukkale Üniversitesi'nin Kanser Erken Teşhis Tarama ve Eğitim Merkezi'nin riskli hastaları sevk ettiği bir merkez olması olabilir. Türkiye'deki anormal smear oranını güncelleyerek daha etkin ve yaygın tarama stratejilerinin geliştirilmesine olanak sağlayacak çok merkezli yeni çalışmalara intiyaç vardır.

Anahtar kelimeler: Papanicolaou smear, servikal kanser, tarama, sıvı bazlı sitoloji.

Kosar Can Ö. Pamukkale Üniversitesi Hastanesi Kadın Hastalıkları ve Doğum Polikliniği'ne başvuran hastaların servikal smear sonuçlarının değerlendirilmesi. Pam Tıp Derg 2022;15:125-131.

\begin{abstract}
Purpose: This study was designed to evaluate the pap smear results obtained from patients who admitted to Pamukkale University Hospital Gynecology and Obstetrics outpatient clinic.

Material and methods: Pap smear results prepared by Sure Path method and reported according to Bethesda 2014 System of women who were applied to Pamukkale University Hospital Gynecology and Obstetrics outpatient clinic between June 2018 and August 2021 were analyzed retrospectively.

Results: The age distribution of the 9982 cases included in the study was between 17-91 and the mean age was $43.98 \pm 12.21$. Results of a total of $9572(95.89 \%)$ women were found to be normal. In the present study, the abnormal smear rate was $1.97 \%$; The rates of atypical squamous cells of undetermined significance, atypical squamous cells cannot exclude high grade squamous intraepithelial lesion, low grade squamous intraepithelial lesion, high grade squamous intraepithelial lesion and atypical glandular cells were $0.98 \%, 0.25 \%, 0.56 \%$, $0.17 \%$ and $0.01 \%$, respectively.

Conclusion: In this study, the abnormal smear rate $(1.97 \%)$ was found to be higher than the study of the Turkish Cervical Cancer and Cervical Cytology Research Group, which included 33 centers published in 2009. This might be due to Pamukkale University is a center where Cancer Early Diagnosis Screening and Education Center refers risky patients. New multicenter studies that will enable the development of more effective and widespread screening strategies by updating the abnormal smear rate in Turkey are required.
\end{abstract}

Key words: Papanicolaou smear, cervical cancer, screening, liquid-based cytology.

Koşar Can O. Evaluation of cervical smear results of patients who were admitted to Pamukkale University hospital obstetrics and gynecology outpatient clinic. Pam Med J 2022;15:125-131. 


\section{Giriş}

Serviks kanseri tüm Dünya'da kadınlarda meme kanseri, kolorektal kanser ve akciğer kanserinden sonra dördüncü sıklıkta görülen kanserdir. GLOBOCAN 2020 veri tabanının sonuçlarına göre Türkiye'nin de içinde olduğu gelişmekte olan ülkelerde, yaşa standardize edilmiş insidans ve ölüm oranlarında kadınlarda meme kanserinden sonra serviks kanseri (100.000 kişide 18,8 yeni vaka ve 100.000 kişide 12,4 ölüm) ikinci sırada yer almaktadır [1, 2]. Sağlık Bakanlığı'nın Türkiye'de kanser kayıt istatistiklerinin sonuçlarına göre ülkemizde kadınlarda en sık görülen kanser sıralamasında serviks kanseri (100.000 kişide 4,3 yeni vaka) 9. sırada yer almaktadır [2]. Tüm ülkelerde serviks kanseri ciddi bir morbidite ve mortalite sebebi olarak kabul görmekle birlikte, erken tanı/tarama programlarının doğru bir şekilde uygulanmasının önemi her geçen gün daha iyi anlaşılmaktadır.

Serviks kanseri, etyopatogenezi aydınlatılmış ve önlenebilir bir kanser türüdür [3]. Tarama programlarının amacı prekanseröz aşamada lezyonların saptanması ve ölümlerin engellenmesidir. Tarama programlarıyla serviks kanserinin kontrol altına alınması koruyucu hekimliğin başarısını gösterir. 1940'ı yıllarda ilk kez George Papanicolaou tarafından serviksin sitolojik incelemesi yapılmış ve serviks kanserinden yıllar önce kadınların serviksinde anormal hücrelerin varlığını tanımlanmıştır. Bu inceleme Papanicolaou smear, Pap smear (PS) testi olarak adlandırımıştır [4]. Servikal smear taramasını uzun süredir başarıyla uygulayan birçok ülkede serviks kanserinde morbidite ve mortalite $\% 70$ 'in üzerinde azalmıştır [5]. Serviks kanseri doğal seyrinin tarama programlarına uygun olması ve erken tanıyla tedavi edilebilmesi nedeniyle kansere bağlı ölümlerin nadir nedenlerinden biridir. Düzenli olarak taramaya giden hiçbir kadının rahim ağzı kanserinden ölmeyeceğini söylemek bugün için mümkün hale gelebilmiştir. Bu nedenle Dünya Sağlık Örgütü (DSÖ) tüm ülkelerde serviks kanseri taraması yapılmasını önermektedir [6]. Tarama yöntemi ve programları ülkelere göre farklılık gösterebilir [7].

Bu çalışmada, PS testinin çok önemli bir serviks kanseri tarama yöntemi olması sebebiyle; üçüncü basamak sağlık merkezi olan Pamukkale Üniversitesi Hastanesi Kadın
Hastalıkları ve Doğum Polikliniği'ne yaklaşık son üç yıl içerisinde başvuran hastaların PS sonuçlarının değerlendirilmesi amaçlanmıştır.

\section{Gereç ve yöntem}

$\mathrm{Bu}$ retrospektif çalışma, Pamukkale Üniversitesi Girişimsel Olmayan Klinik AraştırmalarEtikKurulutarafındanonaylandıktan sonra Helsinki Bildirgesi ilkelerine uygun olarak başlatılmıştır. Pamukkale Üniversitesi Hastanesi Kadın Hastalıkları ve Doğum Polikliniği'ne Haziran 2018 ile Ağustos 2021 tarihleri arasında başvuran kadınların PS sonuçları değerlendirilmiştir. Bu süreçte kliniğimizde sıvı bazlı PS yöntemi kullanılmıştır. Kliniğimize başvuran hastalardan 21 yaşından büyük ve seksüel aktif yaşam öyküsü olan kadınlara servikal PS önerilmektedir. Ayrıca seksüel aktif yaşam öyküsü olan ve PS testi yaptırmak isteyen kadınlardan alınmaktadır. PS testi yaptırmak isteyen hastaların menstrüel kanamasının olmadığı dönemde, son 72 saat sürecinde koit veya vajinal duş yapmamış ya da vajinal bir ilaç uygulamamış olanlarından öncelikle spekulum vajene yerleştirilip servikal ekstemal os'tan (endoserviks'de dahil) süpürge tarzı smear fırçası 360 derece döndürülerek alınan örnekler sıvı bazlı yöntem ile fikse edilmektedir. PS alındıktan sonra bimanuel muayene ve ultrasonografik değerlendirme yapılmaktadır. Smearler patoloji bölümünde Sure Path SIvı bazlı PS boyama tekniği ile otomatik olarak hazırlanarak, Papanicolaou ile boyanmaktadır. Smear örnekleri patoloji uzmanları tarafından Bethesda 2014 derecelendirme sistemine göre; önemi belirsiz atipik skuamöz hücreler (ASCUS), yüksek dereceli lezyonun dışlanamadığı atipik skuamöz hücreler (ASC-H), düşük dereceli skuamöz intraepitelial lezyon (LSIL), yüksek dereceli skuamöz intraepitelial lezyon (HSIL), atipik glandüler hücreler (AGC) olarak değerlendirilmektedir. Ayrıca Bethesda 2014 derecelendirme sisteminde tariflenen yetersizlik kriterlerine göre değerlendirilmekte; 8000-12000 skuamoz hücre değerlendirme için yeterli olarak kabul edilmektedir [8, 9]. PS test sonuçları sitolojik profil ve yaşa göre gruplandırılarak değerlendirilmiş ve sonuçları tartışılmıştır.

Verilerin istatistiksel analizi SPSS 23.0 (SPSS Inc., Chicago, IL, ABD) programı kullanılarak yapıldı. Verilerin analizinde sürekli değişkenler ortalama \pm standart sapma ve minimum-maksimum aralık şeklinde, kategorik 
değişkenler ise yüzde (\%) oranları verilerek hesaplanmıştır.

\section{Bulgular}

Bu çalışmaya, Pamukkale Üniversitesi Hastanesi Kadın Hastalıkları ve Doğum Polikliniği'ne Haziran 2018 ile Ağustos 2021 tarihleri arasında başvuran kadınlardan alınan toplam 9982 smear verileri dahil edilmiştir. Tablo 1'de PS sonuçlarının yüzdeleri ve yaşları gösterilmektedir. Çalışmaya dahil edilen tüm hastaların yaş dağılımı 17-91 arasında ve

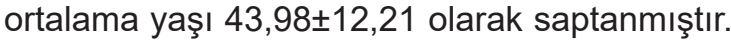
Tüm veriler incelendiğinde 9572 (\%95,89) smear sonucunun normal olarak raporlandığı saptanmıştır. Sayı ve oran olarak anormal smear sonuçları; $98(\% 0,98)$ ASCUS, $25(\% 0,25)$ ASC-H, $56(\% 0,56)$ LSIL, $17(\% 0,17)$ HSIL, 1 $(\% 0,01)$ AGC saptandı. Ayrıca $3715(\% 37,21)$ hastada inflamasyon, $104(\% 1,04)$ hastada kandida, $228(\% 2,28)$ hastada bakteriyel vajinozis, $842(\% 8,43)$ hastada atrofi saptandı. Değerlendirilen $213(\% 2,13)$ olgunun yetersiz hücreler olarak raporlandığı saptanmıştır. Anormal smear oranı \%1,97 idi. Atipik skuamöz hücrelerin, skuamöz intraepitelial lezyona oranı (ASC/SIL) 1,68 idi. Sitolojik sonuçların yaş aralığına göre dağılımı Şekil 1'de

Tablo 1: PS sonuçları ve yaşları

\begin{tabular}{llll}
\hline PS sonuçları & Olgu sayısı(n) & Yüzdesi (\%) & Yaşı** \\
\hline Normal & 9572 & 95,89 & $43,88 \pm 12,13(17-89)$ \\
ASCUS & 98 & 0,98 & $47,11 \pm 13,08(22-77)$ \\
ASC-H & 25 & 0,25 & $54,76 \pm 14,45(27-91)$ \\
LSIL & 56 & 0,56 & $39,57 \pm 11,22(21-75)$ \\
HSIL & 17 & 0,17 & $52,23 \pm 13,87(33-78)$ \\
AGC & 1 & 0,01 & 62 \\
Yetersiz & 213 & 2,13 & $46,28 \pm 13,88(19-87)$ \\
*Inflamasyon & 3715 & 37,21 & $42,52 \pm 10,93(18-89)$ \\
*Kandida & 104 & 1,04 & $37,78 \pm 9,66(18-62)$ \\
*Bakteriyel Vajinozis & 228 & 2,28 & $40,84 \pm 9,59(19-74)$ \\
*Atrofik & 842 & 8,43 & $58,96 \pm 9,22(19-87)$ \\
\hline
\end{tabular}

* Neoplastik olmayan bulgular ve organizmalar

${ }^{* *}$ Veriler ortalama \pm SS (minimum -maksimum) olarak verilmiştir
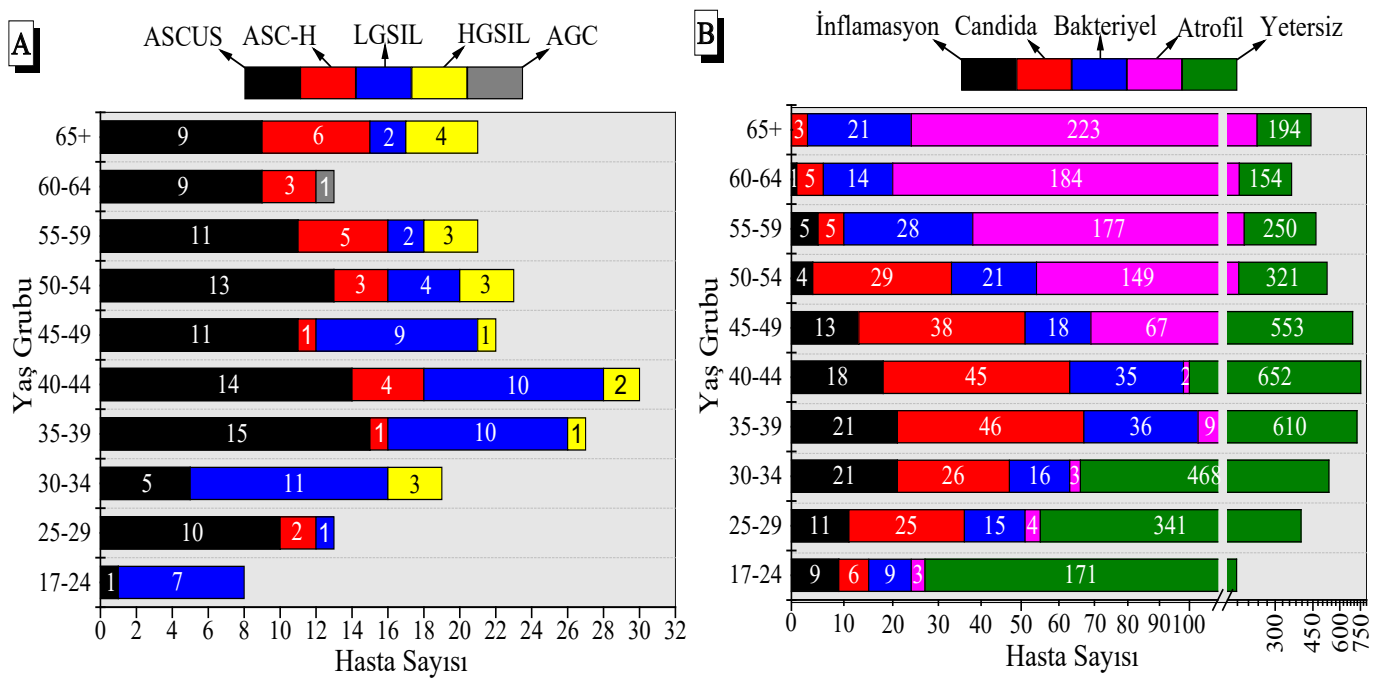

Şekil 1. Sitolojik sonuçların yaş aralığına göre dağılımı 
gösterilmektedir. Değerlendirilen verilerde 25 yaşından küçük 1 hastada ASCUS, 7 hastada LSIL saptanmıştır. Yaş olarak incelendiğinde 30 yaşından küçük 11 hastada ASCUS, 2 hastada ASC-H, 8 hastada LSIL izlenmiştir. Ayrıca 35 yaşından küçük 16 hastada ASCUS, 2 hastada ASC-H,19 hastada LSIL, 3 hastada HSIL bulunmuştur. İncelenen verilerde 50 yaş ve üzeri olan hastalarda 33 ASCUS, 17 ASC-H, 8 LSIL, $10 \mathrm{HSIL}, 1$ AGC bulunmuştur. Bununla birlikte 65 yaşından büyük hastalar arasında 8 ASCUS, 6 ASC-H, 2 LSIL, 3 HSIL saptanmıştır.

\section{Tartışma}

Tüm Dünya'da sık rastlanılan jinekolojik kanserler arasında yer alan serviks kanserinin önlenmesi ya da tedavi edilebilmesi; belirlenen risk faktörleri arasında önlenebilenlerin ortadan kaldırılabilmesi, uygun yaş gruplarındaki kadınlarda uygun tarama yönteminin yapılması ile erken teşhis ve tedavinin yapılabilmesine bağlıdır [10]. Serviks kanseri doğal seyrinin tarama programlarına uygun olması nedeniyle prekanseröz lezyonların erken tanı ve tedavisine olanak sağlayabilmektedir. PS testi ile etkin bir şekilde tarama yapılan gelişmiş ülkelerde çok güzel sonuçlar elde edilmiştir.

Taramanın hangi yaşta başlanacağı konusunda farklı cemiyetlerin farklı önerileri bulunmaktadır. Amerikan Kanser Derneği (ACS) 2020 yılında serviks kanseri tarama programlarıyla ilgili önerilerini güncellemiştir. ACS önerilerine göre; taramaya 25 yaşında başlanılmalı ve yapılabiliyorsa öncelikle 5 yılda bir HPV testi yapılmalıdır ya da 5 yılda bir kotest veya 3 yılda bir sadece PS ile tarama yapılmalıdır. Yeterli tarama yapıldıktan sonra 65 yaş üstü bireylerde tarama sonlandırılabilir. Son $10 \mathrm{yıl}$ içinde ve en son test 3-5 yıl içinde yapılmış ise; ardışık 2 negatif HPV testi ya da 2 negatif kotest veya 3 negatif PS yeterli tarama olarak tanımlanmaktadır [11]. DSÖ 2021 yılında serviks kanseri tarama önerilerini güncellemiştir. DSÖ önerilerine göre; taramaya 30 yaşında başlanılmalı ve yapılabiliyorsa öncelikle 5-10 yılda bir HPV testi yapılmalı ya da 3 yılda bir PS ile tarama yapılmalıdır. Önerilen düzenli tarama aralıklarıyla tutarlı iki ardışık negatif tarama sonucundan sonra 50 yaş üstü kadınlarda tarama sonlandırılabilir. Tarama olanağımız var ise 50-65 yaş aralığındaki kadınlardan hiç tarama yapılmamış olanlara da öncelik verilmelidir [12]. Ülkemizde ise 2008 yılından itibaren Sağlık Bakanlığının Kanser Erken Teşhis Tarama ve Eğitim Merkezi (KETEM) tarafından serviks kanser taraması yapılmaktadır. Toplum tabanlı tarama programında 35-65 yaş arasındaki kadınlar, 5 yılda bir HPV ve PS testi ile taranmaktadır. ACS 2012 yılında tarama yaşını 21 olarak önermekteydi. Sunulan bu çalışmada 25 yaşından küçük 1 hastada ASCUS, 7 hastada LSIL saptanmıştır. Bu vakaların muayene notları tekrar incelendiğinde bir semptom ile başvuran hastalar olduğu, rutin kontrol için gelen hastalar olmadığı gözlenmiştir. Ayrıca 30 yaşından küçük 11 hastada ASCUS, 2 hastada ASC-H, 8 hastada LSIL tespit edilmiştir. Bununla birlikte, 35 yaşından küçük 16 hastada ASCUS, 2 hastada ASC-H, 19 hastada LSIL, 3 hastada HSIL gözlenmiştir. Taramaya başlama yaşı değişiklikleri ile saptanan vaka sayıları farklılaştığı sunulan bu çalışmada görülmüştür. Taramanın sonlandırılacağı yaş konusu üzerinde çok fazla fikir ayrılığı olmamasına karşın, 50 yaşından sonra DSÖ taramayı sonlandırmayı önermektedir. Sunulan bu çalışmada, 50 yaş ve üzeri olan hastalarda 33 ASCUS, 17 ASC-H, 8 LSIL, 10 HSIL, 1 AGC bulunmuştur. Ayrıca 65 yaşından büyük hastalar arasında 8 ASCUS, 6 ASC-H, 2 LSIL, 3 HSIL saptanmıştır. Serviks kanseri tarama programında yaş aralığı toplum şartlarına göre belirlenmesine rağmen bazı durumlarda hasta bazında semptomlara göre karar verilmesinin gerekli olduğu bu çalışmanın sonuçlarından da görülmektedir. Ülkemizde uygulanan tarama programının serviks kanserinin erken tanı ve tedavisine olanak sağlayacağı aşikardır. Fakat tarama yaşının tekrar değerlendirilmesiyle daha fazla vaka tanı ve tedavi şansı bulunacağı bu çalışmanın sonuçlarından anlaşılmaktadır.

PS testinin etkinliğini saptanmasında bazı kalite kontrol belirteçleri de kullanılmaktadır. Anormal smear oranı, ASC/SIL oranı ve ASCUS tanı oranı en sık kullanılan belirteçlerdir. Anormal smear oranı; ASCUS, ASC-H, LSIL, HSIL, AGC ve karsinomların toplamının normal PS'lere oranıdır. Bu oran yüksek gelir düzeyine sahip olan ülkelerde $\% 1,5-7,3$ iken, ülkemiz verilerine göre \%1,2-12,6'dır [13]. ASC/SIL oranı; ASCUS ve ASC-H toplamının LSIL ve HSIL toplamına oranı olarak tanımlanmaktadır. Bazı çalışmalarda bu oran 2-3 arasında, diğer çalışmalarda ise 0,87-4,49 arasında önerilmektedir [13-15]. ASCUS tanı oranının ise $\% 5$ 'den az olması önerilmektedir [13, 15]. 
Bu çalışmada; anormal smear oranı \%1,97, ASC/SIL oranı 1,68 ve ASCUS tanı oranı ise \%0,98 olarak hesaplanmıştır. Oranların hepsi kabul edilebilir değerler arasındadır. Bu sonuçlar hastanemiz patoloji laboratuvarının kalitesini yansıtmaktadır. Bahsedilen kalite kontrol belirteçlerinin kullanımının amacı, smear tekrarı ve ileri incelemelere neden olan belirsiz tanı olarak kabul gören ASCUS oranını azaltmak içindir. Literatürde çeşitli ülkelerde yapılan araştırmalarda PS yetersiz materyal oranları \%0,5-7,2 aralığında değişmekle birlikte ortalama değerin \%0,5 olduğu bildirilmektedir [16-21]. Benzer şekilde daha önce yapılan bir araştırmada Dünya'da ortalama yetersiz materyal oranı \%0,5 olduğu bildirilmektedir [22]. Atılgan ve ark.'nın [23] 2012 yılında Türkiye'de yürüttükleri 3 merkezin dahil olduğu çalışmada yetersiz materyal oranı \%2,1 olarak bildirilmiştir. Sunulan bu çalışmada bulunan \%2,13 yetersiz materyal oranı ortalama değerin üzerinde olmasına rağmen kabul edilebilir aralıkta yer almaktadır.

Türk Servikal Kanser ve Servikal Sitoloji Araştırma Grubu'nun 2009 yılında yayınlanan 33 merkezin dahil olduğu 140.334 hasta sonuçlarının bulunduğu araştırmada, ülkemizde anormal smear oranı \%1,8, ASC/SIL oranı yaklaşık olarak \%2 olarak bildirilmiştir [24]. Sunulan bu çalışmanın sonuçları ile Türk Servikal Kanser ve Servikal Sitoloji Araştırma Grubu'nun bildirdiği sonuçlar benzerlik göstermektedir. Bu çalışmada anormal smear oranı \%1,97 biraz yüksek, ASC/SIL oranı 1,68 ise biraz düşüktür. Bu sonuçlarda yer alan yüksek anormal smear oranı ve düşük ASC/SIL oranı; üniversite hastanesine daha riskli hastaların başvurmasına ve tek merkezli laboratuvarımızın kalitesine bağlı olabileceği düşünülmektedir.

Kuzey Amerika ve Avrupa'da anormal servikal sitoloji oranı ülkemize göre daha yüksektir [23, 24]. Bunun nedeni sosyokültürel farkılıklar, popülasyona dayalı çalışmaların eksikliği veya daha düşük HPV prevalansı olabilir. Amerika Birleşik Devletleri gibi gelişmiş ülkelerde kadınların \%85'i yaşamları boyunca en az bir kez PS testi yaptırırken, gelişmekte olan ülkelerde bu oran sadece \%5'tir [25]. Amerika Birleşik Devletleri'nde yürütülen bir araştırmada anormal smear oranları \%3,9 ASCUS, \%2,1 LSIL, \%0,5 HSIL, \%0,2 AGC olarak bildirilmiştir [23, 24, 26]. Ülkemizde ise yapılan farklı araştırmalarda elde edilen çeşitli sonuçlar mevcuttur. Koç [27] tarafından yürütülen ve 2016 yılında yayınlanan 50.465 vakanın dahil edildiği araştırmada; \%1,95 ASCUS, \%0,37 ASC-H, \%0,73 LSIL, \%0,25 HSIL, \%0,08 AGC gözlemiştir. Şanlıurfa'da yaklaşık 10.000 vakanın dahil edildiği toplum bazlı tarama programında ise \%1,6 ASCUS, $\% 0,06$ ASC-H, \%0,07 LSIL, \%0,02 HSIL, \%0,01 SCC saptanmıştır [28]. Tekin Bayoğlu ve ark. [29] tarafından 2014 yılında doğu Karadeniz'de yürütülen 12.558 vakanın dahil edildiği araştırmada anormal PS sonuçları ise \%56,1 oranında ASCUS, \%2,5 ASC-H, \%17,5 LSIL, \%7,9 HSIL, \%15,3 AGC olarak bildirilmiştir. Seven ve ark. [30] tarafından yürütülen 2015 yılında 7.466 PS sonucunun değerlendirildiği çalışmada anormal PS sonuçları; \%0,77 ASCUS, \%0 ASC-H, \%0,02 LSIL, \%0 HSIL, $\% 0$ AGC olarak bildirilmiştir. Türkiye'de yapılan bu çalışmalarda ortaya konan farklı sonuçlar; araştırmanın yapıldığı zaman, bölge, farklı risk faktörlerine sahip hasta popülasyonu ve hasta sayılarındaki farklılıktan kaynaklanmaktadır. Bu farklılıklar iyi analiz edilip otör cemiyetlerin önerileri dikkate alınarak ülkemize uygun tarama programının düzenlenmesi ile serviks kanserinin daha erken tanı ve tedavisi mümkün olabilecektir. KETEM gibi toplum tabanlı tarama programlarını yürüten birimler belirli yaş grubuna hizmet sunmaktadır. Hekimler tüm kadınlara yönelik çalıştığı için, güncel öneriler dahilinde hastaları bilgilendirmek durumundadır. Serviks kanserinin erken teşhis ve tedavisi için kadın doğum polikliniğine başvuran seksüel aktif yaşam öyküsü bulunan her kadının PS taraması hakkında bilgilendirilmesi ve otör cemiyetlerin önerisi doğrultusunda taranması gerekmektedir.

Bu çalışmada bazı sınırlılıklar bulunmaktadır. Retrospektif bir çalışma olması sebebiyle veriler hasta kayıtlarından elde edilmiştir. Diğer bir sınırlılık ise serviks kanseri tarama yöntemlerinden biri olan HPV sonuçları çalışmaya dahil edilmemiştir. Son olarak, anormal smear takibinde kullanılan kolposkopik biyopsi sonuçlarının incelenmemesi, bu çalışmanın amacı dışında olsa da bir eksiklik olarak kabul edilebilir.

Sonuç olarak, servikal sitoloji anormalliklerinin toplumda rastlanılan sıklığı değişkenlik göstermektedir. Ülkemizi kapsayan 
farklı zamanlarda, farklı bölgelerde yürütülen çalışmalar popülasyonun zaman içinde değişen gerçek oranlarını ortaya koyacak ve daha etkin ve yaygın tarama stratejilerinin geliştirmesine olanak sağlayacağı görülmektedir.

Çıkar ilişkisi: Yazar çıkar ilişkisi olmadığını beyan eder.

\section{Kaynaklar}

1. Sung H, Ferlay J, Siegel RL, et al. Global Cancer Statistics 2020: GLOBOCAN Estimates of Incidence and Mortality Worldwide for 36 Cancers in 185 Countries. CA Cancer J Clin 2021;71:209-249. https:// doi.org/10.3322/caac. 21660

2. Türkyılmaz $M$, Öztürk $M$, Dündar $S$, ve ark. Türkiye Kanser İstatistikleri 2017. Ed. Kara F, Keskinkılıç B. In: Sağlık Bakanlığı Kanser Daire Başkanlığı, Ankara: 2021;23-30. Erişim adresi: https://hsgm.saglik.gov. tr/depo/birimler/kanser-db/istatistik/Turkiye_Kanser_ Istatistikleri_2017.pdf. Erişim tarihi 10 Eylül 2021

3. Muñoz N, Bosch FX, de Sanjosé S, et al. International Agency for Research on Cancer Multicenter Cervical Cancer Study Group. Epidemiologic classification of human papillomavirus types associated with cervical cancer. N Engl J Med 2003;348:518-527. https://doi. org/10.1056/NEJMoa021641

4. Hamankaya I. Comparison of Cervical Smear and Biopsy Results, Journal of Contemporary Medicine 2020;10:613-616. https://doi.org/10.16899/jcm.715815

5. Kitchener HC, Castle PE, Cox JT. Chapter 7: Achievements and limitations of cervical cytology screening. Vaccine 2006;24:63-70. https://doi. org/10.1016/j.vaccine.2006.05.113

6. ARC, Cervix Cancer Screening. IARC Handbook of Cancer Prevention. Vol. 10. 2005, Lyon: IARC Press. 311. Available at: https://publications.iarc.fr/Book-AndReport-Series/larc-Handbooks-Of-Cancer-Prevention/ Cervix-Cancer-Screening-2005. Accessed September 10, 2021

7. Saslow D, Solomon D, Lawson HW, et al. ACS-ASCCPASCP Cervical Cancer Guideline Committee. American Cancer Society, American Society for Colposcopy and Cervical Pathology, and American Society for Clinical Pathology screening guidelines for the prevention and early detection of cervical cancer. CA Cancer J Clin 2012;62:147-172. https://doi.org/10.3322/caac.21139

8. Nayar R, Wilbur DC. The Pap test and Bethesda 2014. 2014;123:271-281. https://doi.org/10.1002/cncy.21521

9. Nayar R, Wilbur DC. The Pap test and Bethesda 2014: "The reports of my demise have been greatly exaggerated. (after a quotation from Mark Twain)". J Low Genit Tract Dis 2015;19:175-184. https://doi. org/10.1159/000381842

10. Sasieni P, Adams J, Cuzick J. Benefit of cervical screening at different ages: evidence from the UK audit of screening histories. Br J Cancer 2003;89:88-93. https://doi.org/10.1038/sj.bjc.6600974

11. Fontham ETH, Wolf AMD, Church TR, et al. Cervical cancer screening for individuals at average risk: 2020 guideline update from the American Cancer Society. CA Cancer J Clin 2020;70:321-346. https://doi. org/10.3322/caac. 21628

12. WHO guideline for screening and treatment of cervical pre-cancer lesions for cervical cancer prevention, second edition [Internet]. Geneva: World Health Organization; 2021. Available at: https://www.who. int/publications/i/item/9789240030824. Accessed September 10, 2021

13. Türkmen IÇ, Başsüllü $N$, Korkmaz $P$, et al. Patients with epithelial cell abnormality in PAP smears: correlation of results with follow-up smears and cervical biopsies. Turk Patoloji Derg 2013;29:179-184. https://doi. org/10.5146/tjpath.2013.01182

14. Nascimento AF, Cibas ES. The ASC/SIL ratio for cytopathologists as a quality control measure. Am J Clin Pathol 2007;128:653-656. https://doi.org/10.1309/ APTVNLP1P0X00CUQ

15. Şahin S, Seçkin S, Seçkin L, Çağlayan E.K, Kara M, Üstün Y. Bozok Üniversitesi'nde incelenen 2279 olguya ait servikal pap smear sonucunun istatistiksel analizi. Bozok Tıp Derg 2014;4:29-32. https://doi. org/10.16919/btd.38037

16. Insinga RP, Glass AG, Rush BB. Diagnoses and outcomes in cervical cancer screening: A population based study. Am J Obstet Gynecol 2004;191:105-113. https://doi.org/10.1016/j.ajog.2004.01.043

17. Yalti S, Gürbüz B, Bilgiç R, Cakar Y, Eren S. Evaluation of cytologic screening results of cervix. Int J Gynecol Cancer 2005;15:292-294. https://doi.org/10.1111/ j.1525-1438.2005.15218.x

18. Gupta S, Sodhani P, Hadler K, et al. Spectrum of epithelial cell abnormalities of uterine cervix in a cervical cancer screening program: Implications for resource limited settings. Eur J Obstet Gynecol Reprod Biol 2007;134:238-242. https://doi.org/10.1016/j. ejogrb.2006.07.022

19. Fonn S, Bloch B, Mabina M, et al. Prevalence of precancerous lesions and cervical cancer in South Africa-a multicenter study. S Afr Med J 2002;92:148-156.

20. Ghazai Aswad S, Gargash H, Badrioatlı P, et al. Cervical smear abnormalities in the United Arab Emirates: a pilot study in the Arabian Gulf. Acta Cytol 2006;50:41-47. https://doi.org/10.1159/000325893

21. Bacanakgil H, Bozkurt T, Çelik S, Dursun N, Pirusa S, Boran B. Servikal smear tarama profil ve sonuçları (4122 olgu). İstanbul Tıp Dergisi 2008;4:178-181.

22. Jones BA, Davey DD. Quality management in gynecologic cytology using interlaboratory comparison. Arch Patbol Lab Med 2000;124:672-681. https://doi. org/10.5858/2000-124-0672-QMIGCU 
23. Atilgan R, Celik A, Boztosun A, Itter E, Yalta T. Ozercan R. Evaluation of cervical cytological abnormalities in Turkish population. Indian $\mathrm{J}$ Pathol Microbiol 2012;55:52-55. https://doi.org/10.4103/03774929.94856

24. Turkish Cervical Cancer and Cervical Cytology Research Group. Prevalence of cervical cytological abnormalities in Turkey. Int $J$ Gynaecol Obstet 2009;106:206-209. https://doi.org/10.1016/j. ijgo.2009.04.003

25. Kuo DY, Goldberg GL. Screening of cervical cancer: Where do we go from here? Cancer Invest 2003;21:157161. https://doi.org/10.1081/cnv-120016410

26. National cancer institute, surveillance epidemiology and end results. Available at: http://seer.cancer.gov/ statfacts/html/cervix.html. Accessed September 10, 2021

27. Koç N. Zeynep Kâmil Kadın Doğum ve Çocuk Hastanesindeki 50,645 servikal smear sonucunun değerlendirilmesi, Zeynep Kâmil Tıp Bülteni 2016;47:3. https://doi.org/10.16948/zktb.36577

28. Özgül N. Türkiye'de serviks kanserinin durumu ve servikal kanser tarama çalışmaları. Tuncer AM. Türkiye'de Kanser Kontrolü. 1. Baskı, Onur Matbaacılık, Ankara. 2007;349-358.

29. Tekin Bayoğlu Y, Güvendağ Güven ES, Mete Ural Ü, Üstüner I, Balık G, Güçer H. Doğu Karadeniz Bölgesindeki kadınlarda anormal servikal sitoloji sonuçlarının değerlendirilmesi. Türk Jinekolojik Onkoloji Dergisi 2014;2:20-24.

30. Seven A, Koçak C, Yüksel KB, Kucur S, Gözükara İ. The evaluation of cervical pap-smear results of the patients who admitted to Obstetrics and Gynecology Clinic of Dumlupınar University Kütahya Evliya Çelebi Training and Research Hospital. Turk J Clin Lab 2015;7:1-4. https://doi.org/10.18663/tjcl.64385

Teşekkür: Yazar, titiz çalışmalarından ve hastaların dosya taramasındaki desteklerinden dolayı Patoloji Uzmanı Doç. Dr. Yeliz Arman KARAKAYA'ya teşekkür eder.

Etik kurul onayı: Çalışma için, Pamukkale Üniversitesi Girişimsel Olmayan Klinik Araştırmalar Etik Kurulu'ndan 03.08.2021 tarih ve 83858 sayı ile onay alınmıştır. 